\title{
Botanical Potency of Chromolaena odorata Linn (Hagonoy) as Mosquitocidal
}

\author{
John Michael Sasan ${ }^{1,2}$, Rengee May Lumantao ${ }^{3}$, Carl Laurence Magallon ${ }^{3}$, \\ Natasha Marie Canillo ${ }^{3}$, Ehrl Rosalita ${ }^{3}$, Marion Anthony Magallon ${ }^{3}$
}

\author{
${ }^{1}$ Research Coordinator, ${ }^{2}$ Lecturer, ${ }^{3}$ Scholar, \\ Department of Science, Technology, Engineering, and Mathematics, PAU Excellencia Global Academy \\ Foundation, Inc., Cebu, Philippines
}

\begin{abstract}
Chromolaena odorata Linn is considered an environmental weed that is traditionally used as a treatment of numerous environmental conditions such as wound healing functions and amelioration of inflammation. In this study, Chromolaena odorata Linn was discovered as an alternative and natural product of mosquitocide. Based on the results gathered and obtained the stem, leaves, and roots are proven to be effective to use rather than using only one part of the plant. Furthermore, the data gathered shows that it only took a small amount of time to kill the mosquito using all parts of the Chromolaena odorata Linn extract. The mosquitocidal activity of Chromolaena odorata Linn had shown its potential significance, ecofriendly, and cost-effective with the presence of botanical phytochemicals (alkaloids, cardiac glycosides, anthocyanin, tannin, and flavonoids) as a source of controlling the mosquito population
\end{abstract}

Keywords: botanical potency, mosquitocidal, chromolaena odorata Linn, mosquitos

\section{INTRODUCTION}

Mosquito bites cause millions of deaths each year worldwide. This represents an increase of well-being risk with mosquito-borne diseases. Mosquito species belonging to genera; Anopheles, Aedes, and Culex, are vectors (Redwane et al., 2002) for the transmission of malaria, dengue fever, yellow fever, filariasis, schistosomiasis, and Japanese encephalitis
(JE), transmitting diseases to more than 700 million people annually (Oyewole et al., 2010; Govindarajan, 2009). Mosquito vectors can transmit several pathogens, including arboviruses, protozoans, and filariae that cause infectious diseases of significant public health concern (Becker $\mathrm{N}$ et al., 2010). To a lesser extent, they may also transmit bacterial diseases (Dieme C., et al 2015).

The World Health Organization (W.H.O. 2012) has recommended vector control as an important component of the global strategy for preventing insecttransmitted diseases. The most commonly employed method for the control of mosquito-borne diseases involved the use of chemical-based insecticide, though it is not without numerous challenges, such as human and environmental toxicity, resistance, affordability, and availability (Ghosh et al., 2012).

The precaution and control of mosquito-borne diseases universally are conducted through an exhaustive technique of pest management. Techniques used for mosquito control incorporate the elimination of breeding sites and the control of mosquito larvae and adults. Therefore, the only way to avoid epidemics of mosquitoborne diseases is through the control of insect vectors and thorough knowledge of its biology, behavior, and environmental factors that facilitate its transmission 
(García-Gutiérrez C, Gómez-Peraza RL, López ACE, León-Váldez A., 2012).

Since its discovery, synthetic insecticides have shown the most strategy used to control mosquito-borne vectors. Synthetic insecticides such as the main synthetic groups are chlorinated hydrocarbons, organic phosphates (organophosphates), and carbamates. On the other hand, modulators of sodium channels (organochlorines, pyrethroids, and pyrethrins), acetylcholinesterase inhibitors (carbamates and organophosphates), and the chloride channel antagonists regulated by the gamma-amino-butyric acid or GABA (organochlorine cyclodiene and phenyl pyrazoles) are also known for their effectiveness. However, the effect of insecticides can be toxic to a host of other organisms. More recently, several human acute and chronic illnesses have been associated with pesticides exposure (Mostafalou and Abdollahi, 2012). Pesticide drift from agricultural fields, exposure to pesticides during the application, and intentional or unintentional poisoning generally led to acute illness in humans (Dawson et al., 2010; Lee et al., 2011b). Several symptoms such as headaches, body aches, skin rashes, poor concentration, nausea, dizziness, impaired vision, cramps, panic attacks, and in severe cases coma and death could occur due to pesticide poisoning (Pan-Germany, 2012). The severity of these risks is normally associated with toxicity and quantity of the agents used, mode of action, mode of application, length and frequency of contact with pesticides, and the person that is exposed during application (Richter, 2002).

In recent years, scientists and locals have increasingly recognized the potentials of a variety of botanicals (extracts and powders from plant parts) to control insect pests (Rajmohan and Logankumar, 2011) including stored products pests (Onunkun, 2013; Lawal et al., 2015). Phytochemical from plants has been a reliable source of mosquito egg and larval control agents, which are a bountiful source of bioactive compounds that are easily biodegradable into non-toxic products. In fact, many researchers have reported the effectiveness and benefits of derivatives present in plants or essential oils against mosquito larvae. They act as larvicides, insect growth regulators, repellents, and oviposition attractants (Pushpanathan, 2008; Samidurai et al., 2009; Mathivanant et al., 2010). Due to their environmental advantages, the use of insecticides of vegetable origin in pest management has been increasing [Leyva $M$, Marquetti MdelC, French L, Montada D, Tiomno O, Tacoronte JE. 2013). The biological control of mosquito larvae with predators and other biological control agents could be a more effective and environmentally friendly strategy, thus avoiding the use of synthetic chemicals and the consequent environmental damage [Kumar R, Hwang JS.2006].

Chromolaena odorata is a weed that belongs to the Asteraceae family which is commonly known as Hagonoy in the Philippines. The weed goes by many common names including; Siam weed, devil weed, French weed, communist weed (Vaisakh and Pandey, 2012). The efficiency of healing wounds comes from the antioxidant property of the drug or plant which enhances conserving the fibroblast and keratinocyte proliferation on those wounds Vaisakh MN, Pandey A. (2012). C. odorata is popularly used for traditional wound healing in Vietnam; moreover, the leaf aqueous extract has been used for the treatment of soft-tissue burns or skin infections (Phan TT, Wang L, See P, Grayer RJ, Chan SY, Lee ST Biol Pharm Bull. 2001, Thang PT, Patrick S, Teik LS, Yung CS Burns. 2001, Phan TT, Hughes MA, Cherry GW Plast Reconstr Surg. 1998). Previous phytochemical studies of the leaf extracts of C. odorata show the presence of alkaloids, cardiac glycosides, anthocyanin, tannin, and flavonoids (Ngozi et al., 2009). Some studies also demonstrate the efficacy of its leaf extract, as an antioxidant, antiinflammatory, analgesic, anti-microbial, and cytoprotective agent (Ajao et al., 2011). The 
oil from C. odorata also had been exploited as an insecticide, ovicide, and larvicide (Noudogbessi et al., 2006).

\section{MATERIALS AND METHODS 1. Description of Study Area}

The Hagonoy plant is a weed species with a single, soft, and dark green tree and leaves and is commonly located in the Philippines. The Plant was obtained from the backyard, and its fresh leaves, herbaceous stem. and its basal end, roots were subjected to serve as a biotic potential and protectants against mosquitoes. The active ingredient found in the Hagonoy plant is responsible for the massive mosquito elimination action.

\section{Experimental of test animals}

13 mosquitoes (Culex pipiens) were used and assigned in seven groups were placed in their container in every group of mosquitoes by using spray technique. The first batch (2 mosquitoes) on the botanical extract of fresh hagonoy leaves in the container. The second batch (2 mosquitoes) on a botanical extract of fresh hagonoy herbaceous stem. Third Batch (2 mosquitoes) on the herbal extract of fresh hagonoy roots. Fourth Batch (1 mosquito) on the herbal extract of veiny roots and green leaves. Fifth Batch (1 mosquito) on the botanical extract of brown roots and vascular plant stem. Sixth Batch (1 mosquito) on the botanical extract of foliage and soft stem. Seventh Batch (4 mosquitoes) on the botanical extract of the whole hagonoy plant.

\section{Plant material}

In the preparation of Mosquitocidal, the following materials were used: Fresh hagonoy weed, tap water, kitchen knife, chopping board, blender, digital weighing scale, thermometer, net, measuring cup, pot pan, scissor, transparent container, funnel, strainer, and small flacon spray for containing the extract.

\section{Extraction Procedure}

Hagonoy plants (leaves, stems, roots) were collected personally. Dirt was taken out from the leaves up to roots by flushing with clean water. The stems and roots were separated from their leaves manually and were put in a separate container. The leaves and stem were turned into smaller pieces by the use of a kitchen knife and chopping board while the roots were set aside and left unharmed. Sequentially, leaves and stems were turned into much smaller pieces by the use of a blender. Collect each extract by strainer and put it in the container. Afterward, get the pot pan and boil the hagonoy roots. Wait for 5 minutes, pour the solution through a strainer and remove the roots. Each filtrate we're placed on a small flacon spray using a funnel and stored in a cool dry place away from direct sunlight. Ready to test.

\section{Exposure technique of test organism}

The fresh Chromolaena Odorata contained certain extract parts of (See the following Table A, B, C, and its observing reaction)

TABLE A.

\begin{tabular}{|l|l|l|l|l|}
\hline PARTS & Weight & Water & Product Mixture & Temperature \\
\hline LEAVES & $1.0 \mathrm{~g}$ & $100 \mathrm{ml}$. lukewarm water & $60 \mathrm{ml}$. & $33.7^{\circ} \mathrm{C}$ \\
\hline STEM & $1.0 \mathrm{~g}$ & $100 \mathrm{ml}$. lukewarm water & $60 \mathrm{ml}$. & $32.8^{\circ} \mathrm{C}$ \\
\hline ROOTS & $0.6 \mathrm{~g}$ & $200 \mathrm{ml}$ & $160 \mathrm{ml}$ & $41.1^{\circ} \mathrm{C}$ \\
\hline
\end{tabular}

\begin{tabular}{|c|c|c|c|}
\hline \multicolumn{4}{|c|}{ FIRST BATCH (LEAVES) } \\
\hline \multicolumn{2}{|c|}{ 1st Mosquito } & \multicolumn{2}{|c|}{ 2nd Mosquito } \\
\hline ATTEMPT & TIME & ATTEMPT & TIME \\
\hline 1st spray & 2 mins. and 10 secs. & 1st spray & 2 mins. and 25 secs. \\
\hline 2nd spray & 2 mins. & 2nd spray & 1 min. and 31 secs. \\
\hline 3rd spray & $1 \mathrm{~min}$. and 50 secs. & 3rd spray & 57 secs. \\
\hline
\end{tabular}

The first mosquito shows that the first spray was making the mosquito lightheaded and unable to fly. Then, the second spray was dormant. Lastly, the third spray made the mosquito convulse. 
The second mosquito demonstrates how the initial spray rendered the mosquito getting weak. The second spray was then apathetic. The third spray caused the mosquito to inert.

\begin{tabular}{|c|c|c|c|}
\hline \multicolumn{4}{|c|}{ SECOND BATCH (STEM) } \\
\hline \multicolumn{2}{|c|}{ 1st Mosquito } & \multicolumn{2}{|c|}{ 2nd Mosquito } \\
\hline ATTEMPT & TIME & ATTEMPT & TIME \\
\hline 1st spray & 2 mins. and 6 secs. & 1st spray & 2 mins. and 22 secs. \\
\hline 2nd spray & 1 min. and 42 secs. & 2nd spray & 1 min. and 42 secs. \\
\hline 3rd spray & 1 min. and 32 secs. & 3rd spray & 1 min. and 6 secs. \\
\hline 4th spray & 1 min. and 28 secs. & 4th spray & 56 secs. \\
\hline
\end{tabular}

The first mosquito shows frailness in the first spray. Secondly, the mosquito exhibits a drained appearance. In the third spray, the mosquito is already weak and the last spray made the mosquito barely move.

The second mosquito shows that the first spray was making the mosquito unable to fly. The second spray is making the mosquito grow weaker. Then, the third spray compels mosquito exhaustion. Finally, the fourth spray where the mosquito is barely alive.

\begin{tabular}{|l|l|l|l|}
\hline \multicolumn{2}{|l|}{ THIRD BATCH (ROOTS) } \\
\hline 1st Mosquito & 2nd Mosquito \\
\hline ATTEMPT & TIME & ATTEMPT & TIME \\
\hline 1st spray & 1 min. and 38 secs. & 1st spray & 1 min. and 47 secs \\
\hline 2nd spray & 1 min. and 49 secs. & 2nd spray & 1 min and 30 secs \\
\hline 3rd spray & 1 min. and 6 secs. & 3rd spray & 1 min and 28 secs \\
\hline 4th spray & 49 secs. & 4th spray & 45 secs. \\
\hline
\end{tabular}

The first mosquito in the first spray is still energetic. Second, the mosquito was slowly getting tired. Thirdly, the mosquito is unable to fly. In the fourth spray the mosquito is already non-movable.
The first spray of the second mosquito is lively as it was caught. Second, the mosquito is already exhausted. The third spray shows that the mosquito is worn out. And the last spray the mosquito is hardly alive.

TABLE B.

\begin{tabular}{|l|l|l|l|l|}
\hline & EXTRACT & TEMPERATURE & PRODUCT MIXTURE & TEMPERATURE \\
\hline ROOTS AND LEAVES & Roots $20 \mathrm{ml}$. & $41.1^{\circ} \mathrm{C}$ & $40 \mathrm{ml}$. & $\mathrm{L}{ }^{\circ} \mathrm{C}$ \\
\cline { 2 - 3 } & Leaves $20 \mathrm{ml}$. & $33.7^{\circ} \mathrm{C}$ & & \\
\hline \multirow{2}{*}{ ROOTS AND STEM } & Roots $20 \mathrm{ml}$ & $41.1^{\circ} \mathrm{C}$ & 40 & $\mathrm{~L}^{\circ} \mathrm{C}$ \\
\cline { 2 - 3 } & Stem $20 \mathrm{ml}$ & $32.8^{\circ} \mathrm{C}$ & & \\
\hline \multirow{2}{*}{ LEAVES AND STEM } & Leaves $30 \mathrm{ml}$ & $33.7^{\circ} \mathrm{C}$ & $40 \mathrm{ml}$ & $\mathrm{L}^{\circ} \mathrm{C}$ \\
\cline { 2 - 3 } & Stem $10 \mathrm{ml}$ & $35^{\circ} \mathrm{C}$ & & \\
\hline
\end{tabular}

\begin{tabular}{|c|c|}
\hline \multicolumn{2}{|c|}{ FOURTH BATCH (ROOTS AND LEAVES) } \\
\hline \multicolumn{2}{|c|}{1 Mosquito } \\
\hline ATTEMPT & TIME \\
\hline 1st spray & 1 min. and 35 secs. \\
\hline 2nd spray & 1 min. and 20 secs. \\
\hline 3rd spray & 1 min. and 10 secs. \\
\hline 4th spray & 55 secs. \\
\hline
\end{tabular}

The initial spray did make the mosquito tired. After that, the second spray shows it is incapable of moving. In the third spray, the mosquito appears to be exhausted. Finally, in the fourth spray, the mosquito exhibits unmoving action.

\begin{tabular}{|l|l|}
\hline \multicolumn{2}{|l|}{ FIFTH BATCH (ROOTS AND STEM) } \\
\hline 1 Mosquito \\
\hline ATTEMPT & TIME \\
\hline 1st spray & 1 min. and 41 secs. \\
\hline 2nd spray & 1 min. and 21 secs. \\
\hline 3rd spray & 1 min. and 14 secs. \\
\hline 4th spray & 58 secs. \\
\hline
\end{tabular}


The first spray shows that the mosquito is still lively. The second spray portrays the mosquito lightheaded. In the third spray, the mosquito displayed worn-out behavior. In the fourth or the last spray, the mosquito is unmoving or barely alive.

\begin{tabular}{|l|l|}
\hline \multicolumn{2}{|l|}{ SIXTH BATCH (LEAVES AND STEM) } \\
\hline 1 Mosquito \\
\hline ATTEMPT & TIME \\
\hline 1st spray & 1 min. and 36 secs. \\
\hline 2nd spray & 1 min. and 25 secs. \\
\hline 3rd spray & 1 min. and 3 secs. \\
\hline 4th spray & 50 secs. \\
\hline
\end{tabular}

The initial spray displayed the mosquito to be quite dizzy. The second spray of the mosquito is physically weak. Third, the mosquito is already flightless. Fourth, the mosquito is shown to be in a state of barely moving.

\begin{tabular}{|l|l|l|l|}
\hline \multicolumn{4}{|c}{ TABLE C. } \\
\hline PARTS & EXTRACT & PRODUCT MIXTURE & TEMPERATURE \\
\cline { 2 - 2 } $\begin{array}{l}\text { LTEM AND } \\
\text { ROOTS }\end{array}$ & Leaves $40 \mathrm{ml}$. & $90 \mathrm{ml}$. & $32.9^{\circ} \mathrm{C}$ \\
\cline { 2 - 2 } & Stem $20 \mathrm{ml}$ & & \\
\cline { 2 - 2 } & Roots $30 \mathrm{ml}$ & & \\
\hline
\end{tabular}

\begin{tabular}{|l|l|l|l|}
\hline \multicolumn{3}{|l|}{ SEVENTH BATCH (All Extract) } \\
\hline 1st Mosquito & \multicolumn{2}{l|}{ 2nd Mosquito } \\
\hline ATTEMPT & TIME & ATTEMPT & TIME \\
\hline 1st spray & 2 mins. and 20 secs. & 1st spray & 1 min. and 27 secs. \\
\hline 2nd spray & 1 min. and 38 secs. & 2nd spray & 51 secs. \\
\hline 3rd spray & 50 secs. & 3rd spray & 29 secs. \\
\hline 3rd Mosquito & 4th Mosquito \\
\hline ATTEMPT & TIME & ATTEMPT & TIME \\
\hline 1st spray & 1 min. and 30 secs. & 1st spray & 1 min. and 3 secs. \\
\hline 2nd spray & 1 min. and 1 sec. & 2nd spray & 39 secs. \\
\hline 3rd spray & 40 secs. & 3rd spray & 34 secs. \\
\hline
\end{tabular}

The first spray of the first mosquito unable to fly. The second spray appears to be already exhausted. The third spray displayed the mosquito to have vanished.

The first spray already shows that the second mosquito was incapable of flying. The second spray shows inefficient walking of the mosquito. Third, the mosquito looks like it is dying slowly.

The more you test you conduct the more you discover the product's effectiveness. This mosquitocide indicates a shelf life of at least a week and it is advised to use it immediately to avoid product contamination for more efficient results.

\section{RESULT AND DISCUSSIONS}

The efficacy of Chromolaena Odorata will increase with the large amount and combined all parts of the essential extract of the said parts of the plant. Subsequently, longer exposure of mosquitoes to the extract will be more effective. The phytochemicals extract of all the parts of c odorata was the most potent with a 50 second. This is followed by c. odorata leaves with $1 \mathrm{~min}$. and 50 secs. The data used in these results was the third spray of the first mosquito. The phytochemicals extract of all the parts of c odorata was the most potent with a 50 second. This is followed by c. odorata leaves with $1 \mathrm{~min}$. and 50 secs. The data used in these results was the third spray of the first mosquito. The results showed toxicity variation due to changes in solvents used for the extraction, which could be attributed to chemical constituents, with varying degrees of toxicity, present in each solvent extract. (Ghost et al.,2012)

\section{CONCLUSION}

This study demonstrated that all three plant parts of C. odorata are responsible for the mosquitocidal potential due to their effectiveness in botanical order to obtain safe and efficient natural mosquitocidal activity formulation. The test 
plants can be incorporated into a control strategy or management intervention programs for mosquitoes.

\section{Acknowledgement: None}

\section{Conflict of Interest: None}

\section{Source of Funding: None}

\section{Ethical Approval: Approved}

\section{REFERENCES}

1. Redwane, A., Lazrek, H.B., Bouallam, S., Markouk, M., Amarouch, H., Jana, M. (2002). Larvicidal activity of extracts from Quercus lusitania var. infectoria galls (Oliv.). Journal of Ethnopharmacology, 79, 261-263.

2. Oyewole, I.O., Ibidapo, C.A., Okwa, O.O., Oduola, A.O., Adeoye, G.O., Okoh, H.I., and Awolola, T.S. (2010). Species Composition and Role of Anopheles Mosquitoes in Malaria Transmission Along Badagry Axis of Lagos Lagoon, Lagos, Nigeria. International Journal of Insect Science vol. 2, 51-57.

3. Govindarajan, M. (2009). Bioefficacy of Cassia fistula Linn.(Leguminosae) leaf extract against chikungunya vector, Aedes aegypti (Diptera: Culicidae). European Review for Medical and Pharmacological Sciences, 13, 99-103

4. Becker N, Petric D, Zgomba M, Boase C, Dahl C, Madon M, et al. Mosquitoes and their control. 2nd ed. Heidelberg: Springer; 2010.

5. Dieme C, Bechah Y, Socolovschi C, Audoly $\mathrm{G}$, Berenger JM, Faye $\mathrm{O}$, et al. Transmission potential of Rickettsia felis infection by Anopheles gambiae mosquitoes. Proc Natl Acad Sci USA. 2015;112:8088-93.

6. WHO. (2012). Malaria Report. Geneva, Switzerland.

7. Ghosh, A., Chowdhury, N., and Chandra, G. (2012). Plant extracts as potential mosquito larvicides. Indian Journal of Medical Research, 135, 581-598,

8. García-Gutiérrez C, Gómez-Peraza RL, López ACE, León-Váldez A. Insecticidas bio- rracionales para el control de mosquitos y moscas negras en Sinaloa. Ra Ximhai. 2012; 8: 47-55.

9. Mostafalou S, Abdollahi M. Concerns of environmental persistence of pesticides and human chronic diseases. Clinical and Experimental Pharmacology 2012;S5:e002. (http://dx.doi.org/10.4172/2161-1459.S5e002 ).

10. Dawson AH, Eddleston M, Senarathna L, Mohamed F, Gawarammana I, Bowe SJ, Manuweera G, Buckley NA. Acute human lethal toxicity of agricultural pesticides: a prospective cohort study. PLoS Medicine 2010;7:e1000357.

11. Lee SJ, Mehler L, Beckman J, DieboltBrown B, Prado J, Lackovic M, Waltz J, Mulay P, Schwartz A, Mitchell Y, MoragaMcHaley S, Gergely R, Calvert GM. Acute pesticide illnesses associated with off-target pesticide drift from agricultural applications: 11 States, 1998-2006. Environmental Health Perspectives 2011b;119:1162.

12. Pan-Germany. Pesticide and health hazards. Facts and figures. 2012;1-16 (www.pan germany.org/download/Vergift_EN201112-web.pdf) (accessed on 14 October 2013).

13. Richter ED. Acute human pesticide poisonings. Encyclopedia of Pest Management 2002;3-6.

14. Rajmohan, D; Logankumar, K (2011). Studies on the insecticidal properties of Chromolaena odorata (Asteraceae) against the life cycle of the mosquito, Aedes aegypti (Diptera: culicidae). Journal of Research in Biology 4: 253-257.

15. Onunkun, O (2013). Studies on the repellent activities of four common Asteraceae in Nigeria against red flour beetle, Tribolium castaneum. The International Journal of Engineering and Science 2(12): 90-93.

16. Lawal, OA; Opoku, AR; Ogunwande, IA (2015). Phytoconstituents and insecticidal activity of different solvent leaf extracts of Chromolaena odorata L., against Sitophilus zeamais (Coleoptera: Curculionidae). European Journal of Medicinal Plants 5(3): 237-247.

17. Pushpanathan,T., Jebanesan, A., and Govindarajan, M. (2008). The essential oil of Zingiber officinale Rosc (Zingiberaceae) as a mosquito larvicidal and repellent agent against the filarial vector Culex 
quinquefasciatus (Say) (Diptera: Culicidae). Parasitology Research; 102, 1289-1291.

18. Samidurai, K., Jebanesan, A., Saravanakumar, A., Govindarajan, M., and Pushpanathan, T. (2009). Larvicidal, ovicidal and repellent activities of Pemphis acidula (Lythraceae) against filarial and dengue vector mosquitoes. Academic Journal of Entomology, 2, 62-66

19. Mathivanan, T., Govindarajan, M., Elumalai, K., Krishnappa, K., and Ananthan, A. (2010). Mosquito larvicidal and phytochemical properties of Ervatamia coronaria (Family: Apocynaceae); Journal of Vector Borne Diseases, 47, 178-180

20. Leyva M, Marquetti MdelC, French L, Montada D, Tiomno O, Tacoronte JE. Efecto de un aceite de trementina obtenido de Pinus tropicalis Morelet sobre la biología de una cepa de Aedes (Stegomyia) aegypti Linnaeus, 1762 resistente a insecticidas. Anales de Biología. 2013; 35: 75-84.

21. Kumar R, Hwang JS. Larvicidal Efficiency of Aquatic Predators: A Perspective for Mosquito Biocontrol. Zoological Studies 2006;45:447-466.

22. Vaisakh MN, Pandey A. The invasive weed with healing properties: A review on Chromolaena odorata. Int J Pharm Sci Res. 2012;3:80-3. [Google Scholar]

23. Phan TT, Wang L, See P, Grayer RJ, Chan SY, Lee ST. Phenolic compounds of Chromolaena odorata protect cultured skin cells from oxidative damage: Implication for cutaneous wound healing. Biol Pharm Bull. 2001;24:1373-9. [PubMed] [Google Scholar]

24. Thang PT, Patrick S, Teik LS, Yung CS. Anti-oxidant effects of the extracts from the leaves of Chromolaena odorata on human dermal fibroblasts and epidermal keratinocytes against hydrogen peroxide and hypoxanthine-xanthine oxidase induced damage. Burns. 2001;27:319-

25. Phan TT, Hughes MA, Cherry GW. Enhanced proliferation of fibroblasts and endothelial cells treated with an extract of the leaves of Chromolaena odorata (Eupolin), an herbal remedy for treating wounds. Plast Reconstr Surg. 1998; 101:756-65. [PubMed] [Google Scholar]

26. Ngozi, M., Ikewuchi C. J. and Ikewuchi C. C. (2009). Chemical Profile of Chromolaena odorata (L) Leaves. Pakistan Journal of Nutrition, 8 (5): 521-524.

27. Ajao, A. T., Ajadi, T.S. and Oyelowo, M.S. (2011). Evaluation of Multiplicative Killing Effect of C.odorata extracts and $\beta$-lactam antibiotics against $\beta$-lactamase Producing bacteria, isolated from Selected Hospitals in Ilorin Metropolis. Annals of Biological Research Scholars Research Library, 2, (4), 76-84.

28. Noudogbessi, J-P., Kossou, D. and Sohounhloué, D.C.K. (2006). Composition chimique et Propriétés Physico-Chimiques des Huiles Essentielles de Pimenta racemosa (Miller) 82 et de Chromolaena odorata (L. Robinson) Acclimatées au Bénin. J. Soc. Ouest-Afr. Chim., 026, 11-19

29. Ghosh, N. Chowdhury, and G. Chandra, "Plant extracts as potential mosquito larvicides” Indian J Med Res 135, pp 581598, 2012.

How to cite this article: Sasan JM, Lumantao RM, Magallon CL et.al. Botanical potency of chromolaena odorata Linn (hagonoy) as mosquitocidal. International Journal of Science \& Healthcare Research. 2021; 6(4): 228-234. DOI: https://doi.org/10.52403/ijshr.20211033 